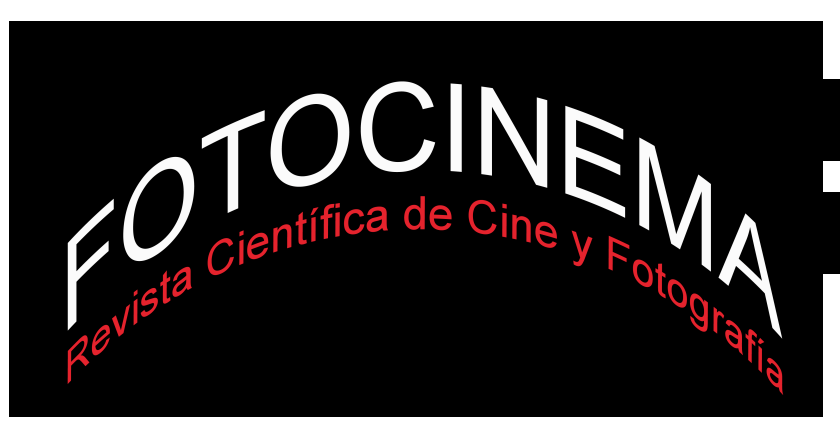

\title{
THEO ANGELOPOULOS, PAISAJE, HOMBRE. ENTRE LA TRAGEDIA GRIEGA DE LA HISTORIA Y LA DESGRACIA DE LOS HOMBRES
}

\section{THEO ANGELOPOULOS, LANDSCAPE, MAN. AMONG THE GREEK TRAGEDY OF HISTORY AND THEMISFORTUNE OF MEN}

\author{
Eva Luisa Gómez Montero \\ Universidad Rey Juan Carlos de Madrid (España) \\ eva.gomez.montero@hotmail.com
}

\section{Resumen:}

La Historia griega y la herencia cultural mítica y rural recorren la filmografía de Theo Angelopoulos en obras donde el viaje marca la estructura principal de sus películas a través de la figura de un hombre/personaje. El presente análisis pretende desentramar la moral que le mueve, ya sea existencial o de cualquier otro tipo, así como investigar la naturaleza de su desgracia y el motivo de ésta, fijándose en el papel que adquiere el hombre y de qué manera influyen en él elementos como la Historia, el paisaje y el destino, así como la forma en la que se relacionan entre sí a lo largo del viaje.

\begin{abstract}
:
Greek History, mythical culture and rural culture are all present in Theo Angelopoulos' filmography, in which the journey marks the main structure of his films through the figure of a man/ character. This analysis seeks to unravel the moral that move him, either existential or any other kind, as well as researches the nature of his misfortune and the reason of it, focusing on the role that man takes on and how it affects in him through various elements, such as History, landscape and destiny. Furthermore it examines how each of the elements relates to each other along the journey.
\end{abstract}

Palabras clave:

Theo Angelopoulos; cine griego; tragedia griega; paisaje; análisis fílmico

Keywords:

Theo Angelopoulos; Greek cinema; Greek tragedy; Landscape; Film Analysis 


\section{Introducción. Modelo de análisis, metodología y objetivos}

Grecia es la protagonista en la filmografía de Theo Angelopoulos. La raíz de toda su obra va mas allá de la Historia, no tan conocida debido a la visión mitológica que siempre se ha tenido acerca de este país sobre el forjamiento económico y político de su último siglo.

Mientras el resto de Europa estaba sumergida en la resolución de sus propios problemas, los griegos se ponían frente a su propia Historia, marcada por las guerras balcánicas, las dos guerras mundiales, las pérdidas territoriales, una dictadura militar muy recordada, golpes de estado, varias guerras civiles, ocupaciones y exilios.

Todos estos procesos históricos, cabría afirmar, se asemejan a las memorias sufridas por todo territorio europeo durante las mismas fechas, sin embargo no es el objetivo aquí, sino el contrario, buscando ya no solo en las particularidades de la Historia griega y su cultura mitológica a lo largo del tiempo y el espacio que nos muestra el director, sino la forma en la que han influido en el hombre representado por Theo Angelopoulos. De modo que con el presente análisis se persigue definir la naturaleza del hombre que se ha construido a base de las circunstancias que han pasado a formar parte de él a través de su propio territorio (y los limítrofes) y la relación que existe entre ese sujeto y la perspectiva moral y filosófica desde la que se enfrenta a ese nuevo paisaje.

Para realizar la presente investigación se ha partido de un análisis semiótico del discurso de la obra completa de Theo Angelopoulos desde el punto de vista antropológico, del sujeto que recorre su filmografía y su relación con el entorno, con el objetivo de determinar la representación que realiza sobre el hombre contemporáneo y de su naturaleza ante la Historia.

La pretensión principal es, por tanto, encontrar las características del hombre viajero, tan recurrente en su filmografía, así como acercarse a los motivos que lo impulsan y no tanto la finalidad de su viaje, como las características del mismo que le definen. Durante el proceso también se pretende analizar la manera en la que incorpora la tragedia griega al paisaje 
discursivo para averiguar qué relaciones hay entre la mitología clásica y de qué manera influye en la redefinición que establece de esos personajes.

De esta manera, la metodología a seguir es, primeramente, abordar un repaso sobre las representaciones que Theo Angelopoulos hace sobre el paisaje griego, entendido como la Historia y el hombre que la habita, con el objetivo de encontrar las razones que le mueven durante su viaje, ya sean morales, existenciales o relacionadas con el paisaje que emerge en sus películas, que se ve apoyado en la redefinición de los mitos y en la realidad histórica.

\section{Angelopoulos, paisaje, hombre}

Las guerras están continuamente reflejadas de una u otra forma en la obra del director heleno, ya que le han conmocionado desde su niñez. En El viaje de los comediantes/ O Thiassos (1975): una bandera nazi se alza en silencio en el año 41, los disparos partisanos salvan a la compañía de ser fusilados, las derrotas de la izquierda e incluso la noche del llamado Diciembre Rojo, sirvan de ejemplo. Pero estas representaciones históricas no siempre son así, sino que en ocasiones tienen una forma simbólica. Tales como el desencanto que transmite Paisaje en la niebla / Topio stin Omichli (1988), los fragmentos del comunismo (estatua de Lenin) que navegan rumbo a Alemania por el Danubio (F 1) en La mirada de Ulises/ To Vlemma tou Odyssea (1995), el eterno exiliado en lugar de nadie de Viaje a Citera/Taxidi stin Kythera (1984), o una boda que se celebra de una orilla a otra en Eleni/ Eleni. Trilogia I: To Livadi pou dakryzei, (2004). Sin embargo, y sin a pesar de sus conocidos planos secuencia, movimientos lentos, el aparente estatismo, quietud $\mathrm{y}$ tranquilidad, Angelopoulos documenta las circunstancias que rodean a los hombres con el objetivo de llegar al espectador para que no quede al margen. Demanda, por ende, un espectador activo. 


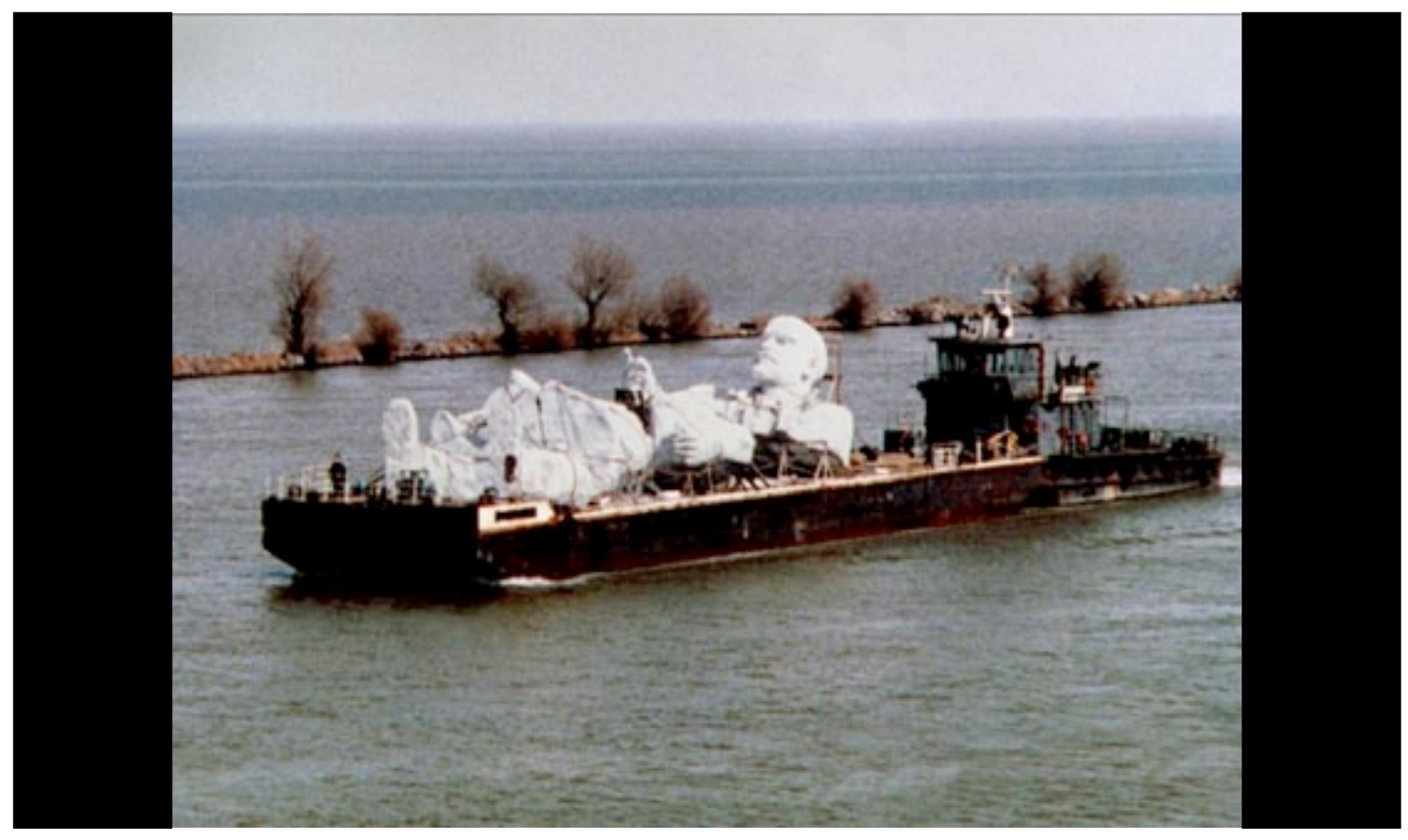

F 1. La mirada de Ulises

Trata temas históricos y nacionales como un drama de gran importancia para reivindicar la identidad propia. Los refugiados de El paso suspendido de la Cigüeña / To Meteoro Vima tou Pelargou (1991) señalaban: «Hemos cruzado la frontera y aún estamos aquí. ¿Cuántas fronteras hay que cruzar para llegar a casa?». La soledad y lo individual toma forma para llegar al carácter introspectivo, el espacio psicológico y las huellas que deja la Historia.

$\mathrm{Al}$ igual que ocurría con los neorrealistas italianos, la frontera entre hombre y personaje apenas existe, resulta bastante confuso determinar dónde empieza uno y dónde acaba el otro. Los personajes de sus películas no tienen el protagonismo clásico de la narrativa tradicional, ya que centra la atención en las ideas y decisiones, el llamado distanciamiento brechtiano que apunta Irini Stathi (Stathi, 2012, p.69). Por tanto, pese a llevar la carga de lo acontecido y pasar por las diferentes etapas del héroe contemporáneo, la mayoría de las veces las circunstancias superan al personaje que pasa a un papel secundario frente al hombre como tal (F 2). 


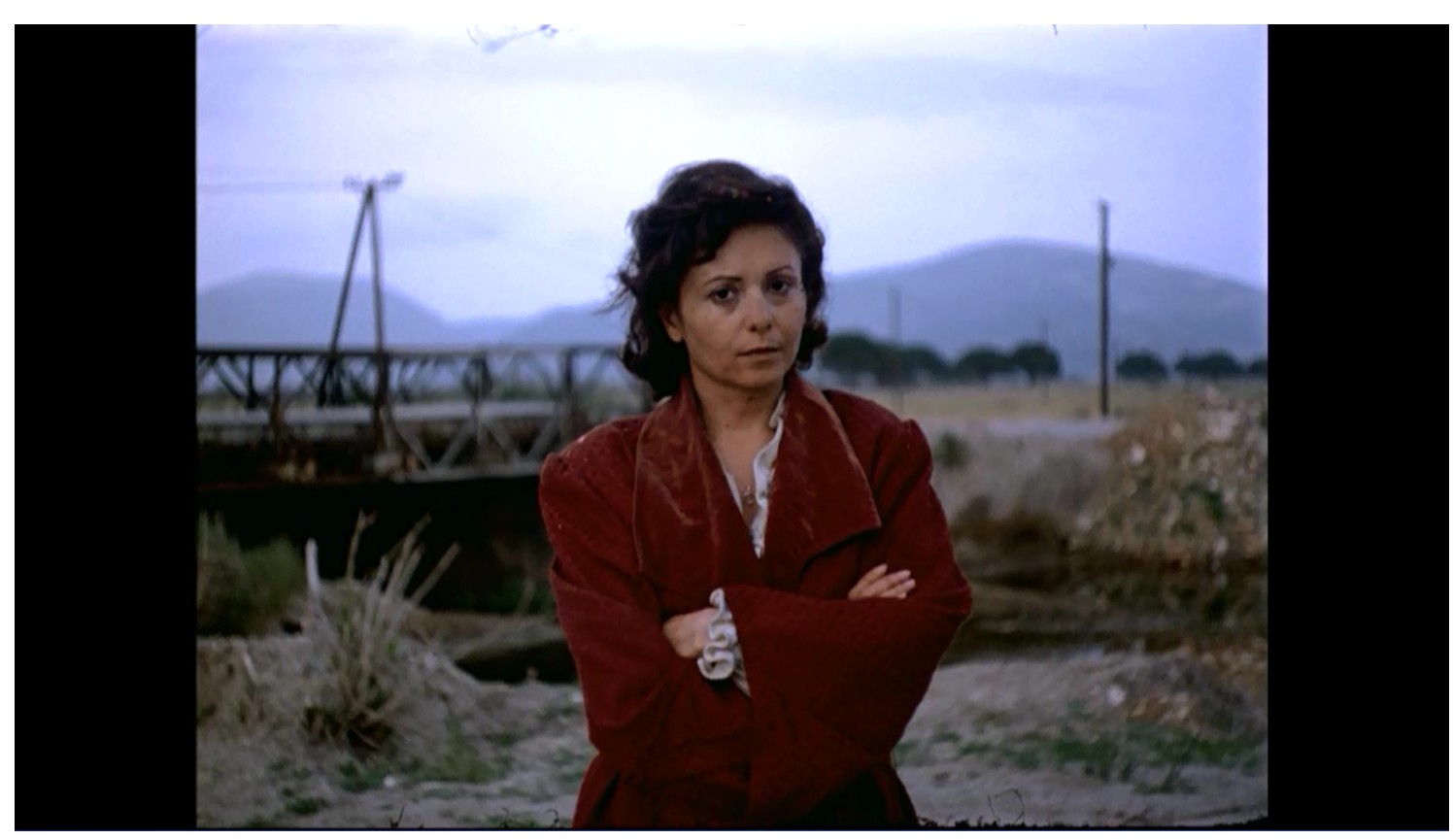

F 2. El viaje de los comediantes

\section{El escepticismo divino como motor terrenal. La caída de la dictadura de la deidad y la no existencia}

Angelopoulos plantea una discusión neoexistencialista, con un debate acerca de si está presente un dios primordial, que está por encima de todo, que imparte justicia y que, como en la antigua Grecia, deja claro a los mortales que no pueden excederse ni en fortuna ni en males para mantener así el equilibrio universal.

Por un lado, cabría sugerir que para Theo Angelopoulos esta diosa, Némesis, está ausente ante el infortunio cometido contra lo natural y contra lo personal. Sin embargo, también cabe la posibilidad de que se estén cobrando las faltas del pasado histórico de Grecia.

En cambio, a pesar de haberse declarado ateo, hay presente una divinidad o entidad superior, por encima de lo visible, omnipresente, que condiciona al hombre, a la naturaleza y al paisaje, que aparecen sometidos por su fuerza. Puesto que el ideal no existe, solo se nos presenta la realidad de la injusticia y sus consecuencias. 
Esta deidad, en unas ocasiones es representada como una dictadura (es el caso de El viaje de los comediantes), en otras una utopía (como ocurre en Paisaje en la niebla), se presenta más como una entidad, no física pero si perenne en el hombre/ personaje, que forma parte de ellos y les hace vagar por el territorio/ país y sus fronteras buscando algo más que cruzar al otro lado, con la esperanza, muchas de las veces, por la necesidad de creer en que existe un lugar tan deseado como buscado. El director griego no deja claras respuestas a estas preguntas, se mueve de forma realista y se ajusta de manera práctica a la realidad que hay que asumir. No se trata de una postura conformista, sino de supervivencia, así como de búsqueda debido, en contraposición, a la pérdida de creencia. Cuando no se cree, se tiende al objetivismo y a la realidad. Esto se traduce en que el director heleno no es pesimista o trágico por los temas que trata, sino que la navaja que utiliza para seccionar el ojo de su sociedad y de su entorno no produce un corte horizontal, sino vertical, lo cual le ayuda (nos ayuda) a asomarse a lo que hay dentro.

Esta situación hace visible un vacío de creencia existencial a través de una ausencia, lo cual no lleva implícito una falta de esperanzas hacia el futuro, o incluso en el propio presente, que se abandona o se resigna ante los cambios sociales y personales; sino que, por el contrario, se presenta como muestra de la impotencia sobre los hechos pasados, así como los que acontecen en el presente (siempre hablando de los tiempos tratados en las películas). De modo que, se apoya en la moral individual y en la fuerza de la búsqueda, para seguir adelante con la creencia de encontrar (porque espera que exista) una Citera interior y no la árida que halla Baudelaire (Baudelaire, 1861 , poema ${ }^{\circ}$ 116).

Bella isla de los mirtos verdes, plena de flores abiertas,

Venerada eternamente por toda nación,

Donde los suspiros de los corazones en adoración

Envuelven como incienso sobre un rosedal. [...]

Habitante de Citerea, hijo de un cielo tan bello,

Silenciosamente tú soportabas estos insultos

En expiación de tus infames cultos

Y de los pecados que te ha vedado el sepulcro. 
Ridículo colgado, itus dolores son los míos!

Sentí, ante el aspecto de tus miembros flotantes,

Como una náusea, subir hasta mis dientes,

El caudal de hiel de mis dolores pasados; [...]

- iAh! iSeñor! iConcédeme la fuerza y el coraje

De contemplar mi corazón y mi cuerpo sin repugnancia! (F 3)

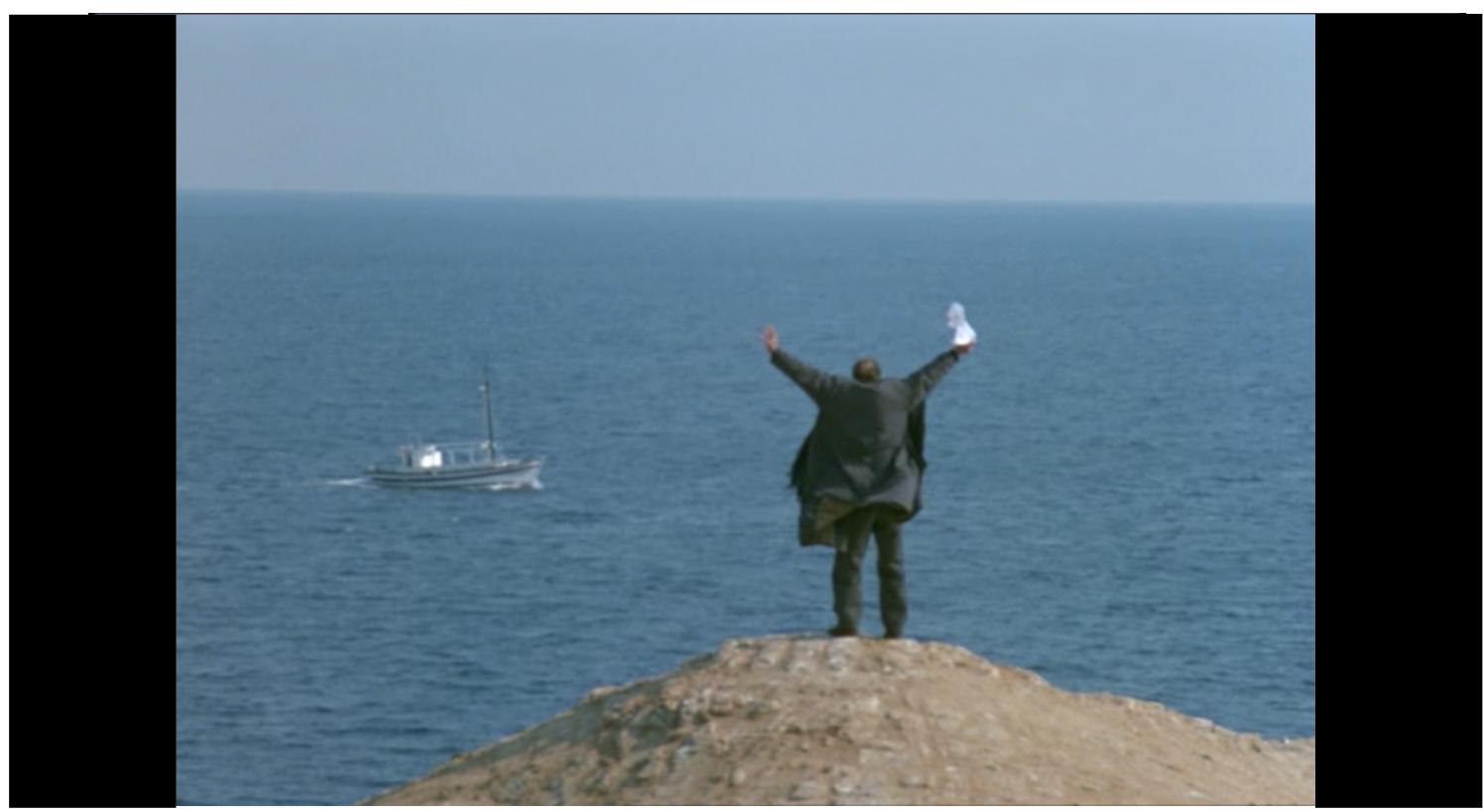

F3. La eternidad y un día

La Grecia que nos muestra Angelopoulos es ésta. Una tierra mítica asociada a los dioses, vistosa y grandiosa, famosa por su riqueza cultural, siempre soleada. Pero, sumergida en un erial, como apunta Baudelaire en este poema, venida a menos e incluso menospreciada, que avergüenza a sus habitantes que están forzados a morir por ella. Por tanto, el escepticismo no es lo único que les mueve, sino un infortunio nada fortuito, ya que no tiene una raíz inesperada o ligada al azar, sino que está predestinado a ocurrir una y otra vez de forma cíclica. Por esto, la melancolía surgida de la esperanza por vivir en un lugar o en una situación mejor, con frecuencia, hace aflorar cierta desesperación en los daños provocados por un pasado-presente que impide avanzar a los protagonistas, aún en contra de su propia voluntad. Se trata de una inmovilidad a la que Theo Angelopoulos los enfrenta durante su viaje de conocimiento. Son personajes perdidos que no encuentran el camino a casa, porque no hay casas, ni sitios acogedores. Refleja de esta manera la incertidumbre del presente, creando dudas durante todo el proceso. La 
naturaleza de lo frágil obliga a los personajes a adaptarse a los cambios que se encuentran. Sin embargo, la vivencia de ese presente y del pasado les mueve a continuar.

\section{Cuando un país se convierte en paisaje}

Angelopoulos prescinde de adornos. Contempla los cambios que tienen lugar en el país/ paisaje con sencillez y austeridad, con el objetivo de conseguir una belleza fea, sucia e incómoda, atípica e incluso molesta en ocasiones. Nos abate, nos hace naufragar y encallar en tierra árida, hunde nuestro ánimo para pedir ayuda, para hacernos reaccionar y encontrar con él, al final del viaje, un atisbo de esperanza, pese a no habernos prometido nada. La pregunta no es dónde está nuestro lugar, sino si existe. No hay certezas durante el viaje, los personajes vagan como fantasmas portando la Historia para intentar cambiar el porvenir que se desdibuja en las fronteras, donde los refugiados mueren por pasar al otro lado, helados de frío, siempre frío, nieve, lluvia y barro.

El director se convierte en testigo participante en una teatralidad cinematográfica. Todo se conforma como una gran epopeya sin héroe, y al igual que los grandes teatros de la Antigua Grecia, el escenario permanece a cielo abierto, recorriendo los alrededores de la capital, así como los países vecinos, las ruinas. La mirada privilegiada en la que se posiciona Theo Angelopoulos no se conforma como mero observador, sino que es un objeto más de la escena, y se mueve dentro de ella, desde la distancia. Es un lugar donde la verdad no se descubre, sino que se impone por sí misma. Somos testigos de campamentos de refugiados en lugar de nadie (La mirada de Ulyses), niños albaneses a la venta entre los escombros de lo que antes era un edificio (La eternidad y un día/ Mia aioniotita kai mia mera, 1998), o una plataforma que aleja a un anciano que no puede reconciliarse con el presente debido su pasado (Viaje a Citera).

El axioma central es una sociedad en decadencia que augura, por otra parte, un mundo nuevo, un renacer, siempre manteniendo la importancia de las 
raíces, de la cultura, de los pueblos que han quedado abandonados no solo tras la Segunda Guerra Mundial, sino tras la Guerra Civil venida después.

- Sin estas dos guerras, ¿̇seguiría siendo Grecia una nación basada en los pueblos?, le pregunta Andrew Horton.

- Claro que los pueblos habrían cambiado de todas maneras, pero no de una manera tan drástica. Los cambios habrían tenido lugar de una forma más gradual, más suave. Tiene que entender que parte del resultado de esas guerras fue que en los años cincuenta 500.000 hombres se marcharon a Alemania, así como a América, Australia, etc., como emigrantes. Eso significó un gran cambio en la vida de los pueblos. De repente, los hombres se habían marchado quedándose solas las mujeres. Con todos esos cambios, el espíritu de los pueblos empezó a morir.

Horton: - ¿Qué espera? ¿Cree que los griegos deberían volver a los pueblos? ¿Debería mudarse la mitad de Atenas?

Angelopoulos: - iNo! No tengo ni ese deseo, ni esa esperanza. Sólo me preocupa que algo bello muriera allí. Es como la desaparición de un gran amor: quieres recordarlo, pensar sobre él, examinarlo. iEs difícil dejarlo marchar! ¿Qué quisiera que ocurriera? Sólo quiero que nuestra vida aquí sea más humana. Ya sabe que hemos perdido muchas cosas en Atenas. El crimen, la contaminación, el tráfico, la impersonalidad de la ciudad, muchas cosas. Necesitamos volver a esos lugares para encontrar muchas de las cosas que siguen siendo importantes, auténticas para nuestra vida (Horton, 2001, p. 173).

La nostalgia que Angelopoulos representa, por tanto, está relacionada con la pérdida de la identidad cultural, la impersonalidad que han supuesto los cambios sociales en aquellos griegos que, debido a la necesidad, abandonaron sus raíces en busca de una vida mejor, más que como anhelo del pasado. Están en un continuo viaje y vagan a la búsqueda sin saber muy bien de qué, pero movidos por el instinto cultural, e incluso natural, de que algo les falta y que necesitan recuperar de nuevo. En cambio, las circunstancias psicosociales en las que se encuentran les impiden ser del todo libres. No son los héroes libres de la tragedia griega en la que tienen permiso para errar (porque ya lo han hecho), sino que se permanecen atados, no 
queda muy claro si a un destino, pero sí a unas circunstancias impuestas, ajenas a sí mismos que no pueden dominar, pero sí actuar cual comediantes siendo continuamente interrumpidos por su propia Historia (tal como ocurre en El viaje de los comediantes).

Cabe diferenciar que mientras que el territorio está referido a la tierra, desde el punto de vista del paisaje tanto cultural, como natural, entendido como las relaciones que existen entre éste y el hombre. Estamos en un lugar social, donde se producen estas conexiones en vertical, pero también en horizontal, o lo que es lo mismo, con los demás territorios que lo conforman, ya sean del mismo país o no (F 4). El país, en cambio, está representado como el símbolo de la frontera física y política. Ante esto, el paisaje es lo que queda. El lugar que se ha desfigurado y que sus habitantes ya no reconocen. No están representados por él, ni tampoco les representa porque ya no les pertenece, se les ha quitado lo natural, de forma que solo les queda su instinto. Nada es como era, nada es como creíamos que era (incluso para un espectador acostumbrado a otra Grecia). De manera que los hombres se mueven por la no pertenencia, no se circunscriben a un lugar, debido a ese auto-desarraigo. Por ello, deambulan buscando algo que se parezca a su antiguo lugar. Quizás una utopía formada por una edad antigua. De esta forma, aunque permanecen en la constante búsqueda de sus raíces y/ u orígenes, tanto personales como cinematográficos, en el caso de La mirada de Ulises, el entorno y las relaciones han hecho que ese hombre no se sienta identificado por una Grecia que desdibuja sus límites territoriales y sociales. Ese sentimiento de desarraigo es, en parte, provocado por ellos mismos. Se separan de un lugar, de su antiguo lugar, que ya no lo es.

En Viaje a Citera se produce el retorno de un hombre tras haber permanecido tiempo fuera, pero cambiado por las circunstancias. Su antiguo lugar ya no lo es. Está descontextualizado y por eso se ve abandonado en una plataforma, en territorio de nadie. La eternidad y un día presenta, como complemento, un hombre que ya no quiere pertenecer al lugar del que todos afirman que es. En su caso, la forma de hacerlo es emprender un viaje de abandono a través de sus recuerdos, a la vez que se da cuenta de que no se 
siente identificado con ese nuevo y amargo paisaje que está emergiendo en el país.

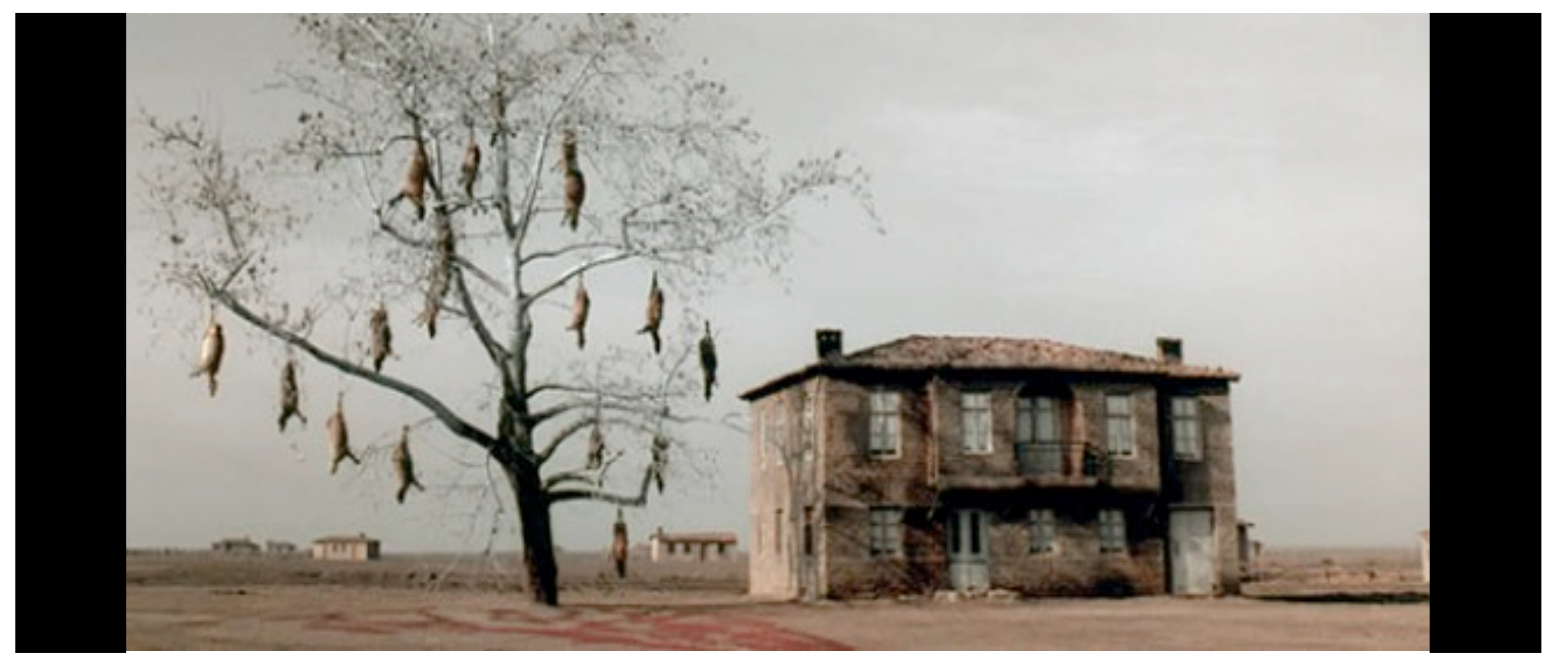

F 4. Eleni

La propia Historia griega convierte al país en un paisaje particular, caracterizado por una parte, por la ruina, ocasionada por el abandono; y, por el otro, por los escombros, como un territorio convertido en un desecho por los restos de las guerras (F 5). La ruina, construida del abandono por una vida o un lugar mejor, en el caso de Angelopoulos tiene dos vertientes: una como reivindicación del abandono de los pueblos por la urbe (por obligación circunstancial), y otra, por la necesidad del encuentro. Por tanto, la sola presencia de los pueblos prácticamente deshabitados de Grecia, ya llevan implícito un pasado, que permanece intrínseco al paisaje del que no se podrán desprender. Este espíritu es el que Angelopoulos rescata para que el actual pueblo nunca olvide los errores cometidos, así como las tragedias vividas por ello, para evitar que no vuelva a ocurrir. Sin embargo, es un pueblo destinado a un ciclo sin fin, donde los hombres intentan calmar su búsqueda moral en el errar en el tiempo. 


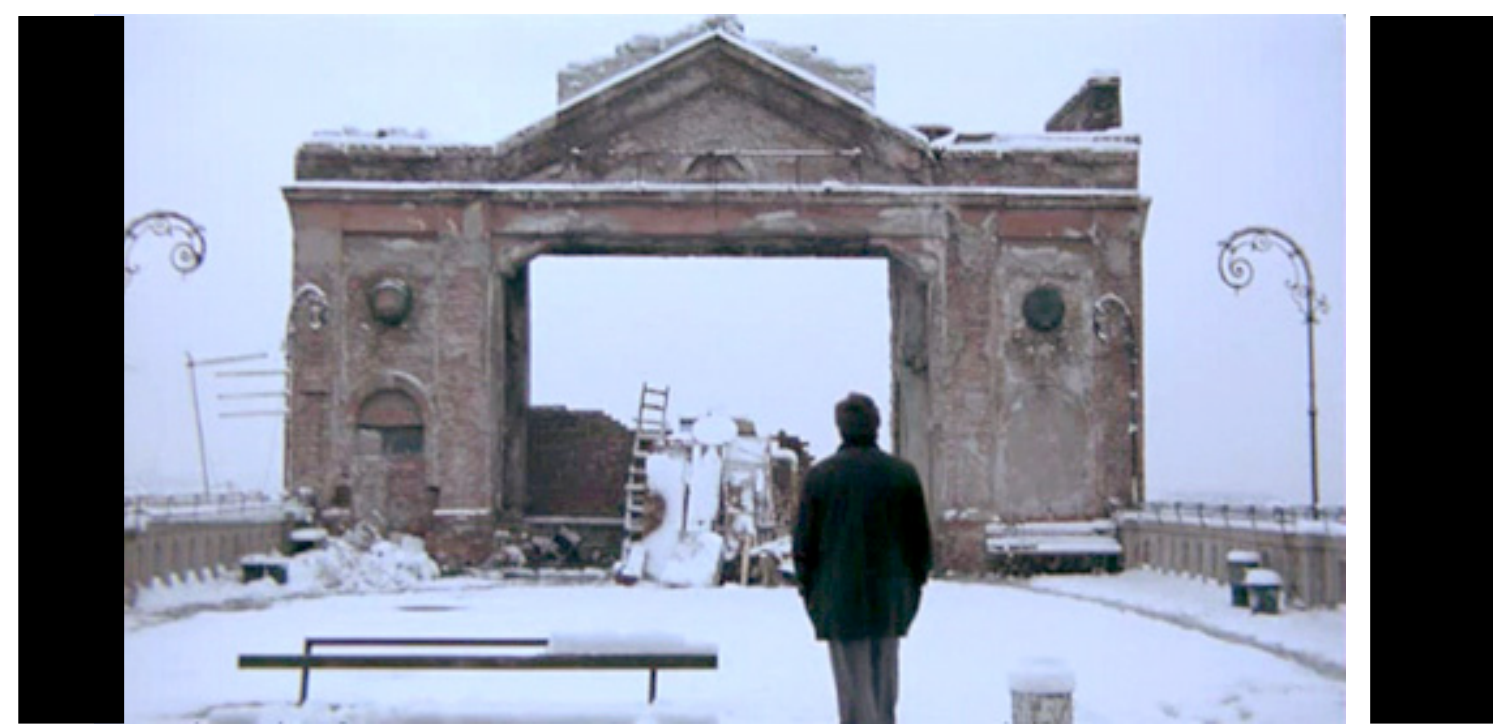

F 5. La mirada de Ulises

Esta postura, tenga o no que ver con la creencia griega de que existe un destino hilado por las Moiras, parecería continua y permanentemente avocada a la desgracia. El hombre que yerra una y otra vez, atrapado en la Historia sin tener ocasión de rehacerla, donde la mano gigante de una estatua que sobrevuela el puerto con el dedo acusador amputado nos apunta haciéndonos culpables (Paisaje en la niebla), únicos responsables. Sin embargo, Angelopoulos deja lugar a la esperanza cuando a pesar de todo dos niños se reconcilian con su árbol-padre (Paisaje en la niebla). Por tanto, rechaza un destino que niegue la libertad del hombre, es por ello por lo que los personajes están en continua lucha interior con su exterior.

\section{No existe nada mas allá de lo que queda del pasado}

La forma en que Angelopoulos transforma su imaginario privado en público resulta en ocasiones hermética. Sin embargo, es ésa forma la que nos indica por dónde continuar con el análisis. No deja al espectador en la libertad de interpretar, sino que lo guía y lo observa para conciliarse (él mismo) con el espacio social y cultural. Cabe preguntarse entonces, ¿qué tipo de espacio social es el que nos presenta? (el espacio cultural está claro). Es aquel en el que las guerras y las revoluciones han destruido las relaciones sociales a base de violencia. No son lugares en los que se vive, sino que sobreviven. 
Las referencias al mito, a la historia y a la cultura popular marcan su cine en las tres divisiones temporales: el pasado como una herida abierta que evidencia un presente desolador, totalmente condicionado por él, pero que conserva cierta esperanza hacia el futuro como única vía para afrontar y superar el hoy del que nos habla. La memoria queda patente como signo de identidad. Las ruinas mediterráneas se presentan olvidadas en un mundo contemporáneo, que apenas reconocemos por el caos y la desorientación. Sin embargo, en Angelopoulos nada cambia, la Historia es un peso pesado para el pueblo que lo condiciona y lo condena a vivir de una forma u otra, abandonándolos a su suerte, ya sea buscando un hogar o así mismos. No existe ninguna identidad que proporcione la tranquilidad anhelada durante siglos de guerras. Por esto, se puede hablar de cierto romanticismo social, unido a un culto por lo natural, y una nostalgia que se torna en belleza. Romanticismo, en cuanto a la libertad en las imágenes, en las ideas, en los sentimientos, en la expresión y en los temas, buscando lo humano, lo nacional, lo heroico, lo divino y lo extraordinario. Angelopoulos huye a lugares alejados de los espacios poblados y artificiales de la sociedad para poder delinear a sus personajes. Se aleja así de la ciudad, Atenas, para adentrarse en la Grecia rural que es la que aparece de forma continua en sus películas: los lugares cercanos al norte del Epiro, en las cercanías de Albania; Macedonia, cerca de la Antigua Yugoslavia; y Tracia, frontera tanto con Turquía como con Bulgaria.

En estos territorios, la naturaleza aparece triste, herida. Es una naturaleza exhausta, cansada de las batallas, dañada y dolida, pero que lleva su propio ritmo y se adecúa a las circunstancias tomando su propia dirección, ya sea buena o mala. No habla, llora su inmovilidad, no es un paisaje cambiante. Aparece frío, caduco, tosco, desamparado de cualquier acto generoso en beneficio de él. En ocasiones, sirva de ejemplo el taxista de La mirada de Ulises, los hombres son capaces de entrar en comunión con la naturaleza, entenderla, hablar con ella y protegerse mutuamente ante la desolación y la incertidumbre. 
La estética de sus películas es poética, recrea lugares de naturaleza decadente. Hay humedad en el ambiente, siempre neblinoso en tonos blancos, grises y azules tanto para lo aéreo, lo volátil, así como para el mar; los tonos marrones y oscuros son utilizados para lo terrenal, lo que permanece enclavado o impregnado a todo aquello que le cuesta avanzar. En cambio, la forma de la narrativa es prosaica, situándose entre el Mythos y el Lógos. El primero, siempre asociado a un discurso largo, narrativo y argumentativo, que resulta fácil de seguir, está en Angelopoulos reinterpretado desde su visión más contemporánea, lo cual lo convierte en algo más que eso, sirviéndole de apoyo para argumentar razonadamente, tal como exige el Lógos que el mito no es más que eso si no se presenta junto a éste para descubrir su verdadera naturaleza.

\section{Conclusiones}

La filmografía revisada para tal análisis demuestra que las películas de Theo Angelopoulos no se tratan únicamente de una revisión mítica de la Historia, sino un conjunto de situaciones sociales, políticas, culturales y personales a través de las fronteras.

El sujeto se define de esta manera y parece persistir durante la filmografía del cineasta como un sello de identidad consustancial a la visión de hombre contemporáneo que construye el director, obligando al diálogo entre el presente y el pasado.

La herencia cultural que refleja durante su obra, principalmente influenciado por la Ilíada y la Orestea, perfilan a un hombre desprovisto de espacio y de tiempo, que viaja por un paisaje no habitable por incómodo, fangoso, siempre bajo una luz tenue, difusa y neblinosa. En este espacio el sujeto ha desencadenado una relación dolorosa no solo con la historia ya vivida, sino también con el presente.

El encuentro que se produce entre el hombre y ese conflicto histórico, tan extrínseco como consustancial, es lo que provoca el enfrentamiento con la 
problemática del propio sujeto, del Yo. El eterno viaje de Odiseo marcado por las guerras y que ve lejana su llegada a casa, ya que nunca existe físicamente.

No hay un hogar a la espera, sino que los personajes transitan cómo y por dónde pueden, a través de las fronteras, para encontrarse a sí mismos y definirse por medio de las decisiones que toman y los obstáculos durante su viaje, ya sean el tránsito a la edad adulta, el abandono, la búsqueda por la nostalgia del pasado, etc.

Por otro lado, Angelopoulos nunca da solución al problema de no tener un lugar, solamente lo plantea tal cual y se mueve en su consecuencia. Se presenta intrínseco al carácter del hombre. La búsqueda del hogar, muchas de las veces no sirve tanto como motor, sino como el camino hacia el conocimiento y reconocimiento dentro de una situación social concreta, muchas de las veces impuesta. Así como el tratamiento de la Historia trágica de la Grecia de Angelopoulos, no es tanto un fin, sino un medio para explicar la desgracia de unos hombres que buscan la comunión moral y existencial con el paisaje y su entorno, reflejo de sus adversidades históricas.

Busca más allá de lo que parece ser probable, de lo esperado, para desembocar en un paisaje, una Historia, que convierte a los hombres en objetos y no en sujetos de la misma. Títeres de un teatro (cinematográfico) contemporáneo que viajan a través de un espacio en el que se sienten desubicados. Sin embargo, por muy desorientados en el viaje, no pierden el ánimo por continuar en busca de una pertenencia que al mismo tiempo les hará libres.

\section{Referencias bibliográficas}

Alberó, Pere (1997). "Caminos desde el exilio. El espíritu de la tragedia en Theo Angelopoulos". Nosferatu, $\mathrm{n}^{\circ}$ 24, San Sebastián.

Alberó, Pere (2000). La mirada de Ulises. Barcelona: Paidós

Alberó, Pere (2012). "La aventura que nunca termina”. Suplemento Culturas de La Vanguardia, 15 de febrero, pp. 25, 26.

Balló, J. (2000). Imágenes del silencio. Barcelona: Anagrama.

Baudelaire, Charles. Un viaje a Citerea. Poema $n^{o} 116$ de Las flores del mal. Edición de 1861 
Chessa, Alberto (2008), Entrevista "Para endulzar el tiempo que pasa”. Revista Minerva, Círculo de Bellas Artes Madrid, octubre.

Company, J. M. (1999). La mirada cautiva. Formas de ver en el cine contemporáneo. Valencia: Generalitat Valenciana, Direcció General de Promoció Cultural i Patrimoni Artistic.

Font, D. (2002). Paisajes de la modernidad cine europeo, 1960-198o. Barcelona: Paidós.

García Gual, Carlos; Guzmán, Antonio (2003). Antología de la literatura griega. VV. AA., Madrid: Alianza Editorial

Herrera, J. (1968). La poesía del cine. Torremolinos (Málaga): Revista Litoral.

Horton, A. (2001). El cine de Theo Angelopoulos. Imagen y contemplación. (Traducción de Vicente Carmona González). Madrid: Akal.

Iglesias, Eulalia (2009). "Al rescate de Angelopoulos”. Cahiers du Cinéma España no 20 , febrero.

Nogué, J. (2007). La construcción social del paisaje. Madrid: Biblioteca Nueva.

Nogué, J. (2008). El paisaje en la cultura contemporánea. Madrid: Biblioteca Nueva.

Riambau, Esteve (1997). "Pasado y presente en los filmes de Theo Angelopoulos. Viajes a través de la Historia". Nosferatu, $n^{\circ}$ 24. San Sebastián.

Roger, A. (2007). Breve tratado del paisaje. (Edición de Javier Maderuelo. Traducción de Maysi Veuthey). Madrid: Biblioteca Nueva.

Stathi, Irini (2012), "Una nueva utopía”, Caimán cuadernos de cine, no 2(53), febrero, pp. 69.

Vidal Estévez, M. (2009). Poemas de la desolación. El cine de Theo Angelopoulos. Edita: Festival de Cine de Huesca.

VV.AA. (2008). Theo Angelopoulos. L’idea del film. (Con estudios de Pere Alberó y Ángel Quintana, una transcripción del seminario de Theo Angelopoulos en la Universidad de Gerona y textos de Silvie Rollet e Irini Stathi). Girona: Documenta Universitaria

VV.AA. (2013). Theo Angelopoulos. El paso suspendido: punto de encuentro. Santander: Shangrila 18-19. Derivas y ficciones aparte.

Zunzunegui, Santos (1994). Paisajes de la forma: ejercicios de análisis de la imagen. Madrid: Cátedra.

Cómo citar: Gómez Montero, E. L. (2014). "Theo Angelopoulos, paisaje, hombre. Entre la tragedia griega de la Historia y la desgracia de los hombres". Fotocinema. Revista científica de cine y fotografía, 9, pp. 282-297. Disponible: http://www.revistafotocinema.com/index.php?journal=fotocinema 